Social AND MANAgement Research JouRnal,

VOL 16, No 1 (2019) 41-54

https://doi.org/10.24191/smrj.v16i1.6080

\title{
The Evaluation and Implementation ON THE Development of Stimulation Setting USing CTML MODEL
}

\section{Mohd Khairul Azlan Rahmat, Siti Zuraida Maaruf}

\author{
Faculty of Education, \\ Universiti Teknologi MARA, \\ Selangor Branch, Campus Puncak Alam, 42300 Puncak Alam, Selangor, \\ Malaysia \\ E-mail: \\ sitiz610@uitm.edu.my
}

Received: 19 October 2018

Accepted: 21 January 2019

Online First: 26 June 2019

\section{ABSTRACT}

This research aimed to identify the possibility and opportunity to implement the stimulation room courseware for drawing studies method in additional and substitute for the outdoor learning and indoor learning method in the teaching and learning of Drawing Studies subject in tertiary level of art education in Malaysia. Thus, this research is conducted in order to develop the stimulation room courseware for drawing studies that will be an optional teaching aid for the subject. This courseware and method will be an integrated use of ICT in the Visual Art Education field. This research was conducted by utilising the design development research (DDR) that consisted of three (3) phases. Phase 1: Needs Analysis, Phase 2: Design and Development and Phase 3: Implementation and Evaluation. However, for the purposed of this article, the researchers will only discuss Phase 3, that is the Implementation and Evaluation phase. The data was collected by the usability test form that has been given to three (3) experts in different fields; one (1) expert on videography, one (1) expert on interface design and one (1) expert on graphic design. The purpose of having this three (3) experts was to evaluate and provide feedbacks on the stimulation room courseware for drawing studies. Pre-test and post-test were carried out by eight (8) students of Art and Design that have undergone the subject 
of Drawing Studies using open-ended questionnaire. The feedbacks were then subjected to evaluation and assessment by two (2) experts in Drawing Studies. Based on the findings, the development of the stimulation method and the courseware is relevant and has possibilities for implementation in tertiary level art education in Malaysia.

Keywords: stimulation room, CTML model, drawing studies, design developmental research, usability test

\section{INTRODUCTION}

This research was conducted in order to develop a stimulation room courseware for drawing studies subject. The aim in developing this stimulation courseware was for it to be used in the stimulation method of drawing studies as a new teaching aid and as a substitute for the outdoor learning method. In this research, the researchers try to explore the possibility and opportunity of the implementation of stimulation method for the teaching and learning of drawing studies.

Nowadays in Malaysia, there are lots of private colleges offering art education based courses, like the schools of Art and Design. Thus, there will be plenty of art learning process that will be taught during this class. One of the main subjects that this student must undergo is a subject called Drawing Studies, which is the core subject for their foundation level. According to National Accreditation Board (Lembaga Akreditasi Negara, LAN), under The Malaysian Qualifications Agency Act 2007 (Malaysian Qualification Agency Act (MQAA), 2007), the programme offered to the student must cover the mastery of body of knowledge; practical skills; social skills and responsibilities. This indicate that the student must be able to master every subject that has been designed and created for the courses according to the syllabus. The MQA clearly stated that students must cover the knowledge of the subjects and drawing studies have become a subject that the student must excel. According to Karczmarzyk (2012), graphic design is a process of visual communication, and problem-solving through the use of type, space, image and colour. As art is now considered as a vital subject in Malaysia's educational system, the importance of learning art methods of teaching art should be discussing in order to find the best way on how the art educators 
can really create the best environment for students to learn art (drawing studies). Therefore, many universities are trying to accommodate to the needs of today's society, prepare for the future challenges, the opportunities and benefits of new teaching technologies (Salinas, 2004) such as the use of Information and Communication Technology (ICT). The function of ICT is to enable the acquisition, production, storage and processing, reporting, recording and presenting information in the form of voice, images and data contained in nature acoustic signals, optical or electromagnetic (Duta, Rivera, 2014). This research will also try to test the implementation of stimulation room method through a courseware that will be used by the students, to see the different outcome from it and compare it to the other method that have been used previously.

The aim in this study is to determine the result of the outdoor and stimulation method and the usability of the stimulation room for drawing studies courseware. This objective will comply with the Implementation and Evaluation in Phase 3 of this research. The results of the findings will determine whether the stimulation room for drawing studies method has the possibilities of implementation.

\section{LITERATURE REVIEW}

Based on the researcher's observation and personal experience, there are currently two private universities in Malaysia that use different types of curricula for teaching drawing studies. This also shows that these two private universities tried two different methods in terms of finding the best way for their student to master drawing. Although these two curricular / methods of teaching have been used for some time now, there are still problems related to them. According to Anderson (2000), learners cannot learn something from imagination and that's the reason why creative classes must be done in a more open environment. They said that the environment of the classrooms has separated them with the mood and ambiance that relates with the subject matter. This relates to the theory of John Ruskin, the famous art critic, who argued that artistic skill is acquired through 'innocence of the eye' (Ruskin, 1856). Meanwhile the outdoor classes might pose safety concerns (Malone, 2008). Some of the students' parents might feel uneasy and unsafe for their children as found by (Dillon, Rickson, et al., 2006). From these statements, 
both methods have its strength and weaknesses. This is the main reason why the researcher came up with the idea of creating a stimulation room for drawing studies so that these students can have the sense of outdoor while drawing in a cosy and more conducive comfort of their classroom. With this stimulation room, the researcher hope that it can become an option of a teaching aid that combines the strength of the outdoor environment and a safe and a well-equipped drawing studies classroom through the stimulation process.

\section{RESEARCH METHODOLOGY}

For this study, the researcher uses the Design Developmental Research (DDR) that have been developed by Richey and Klien (2007) that involves both Qualitative and Quantitative approaches. With the use of DDR approaches, the researcher will get a systematic study of designing, developing and evaluating instructional programmes, process and products that meet the criteria needed by the researcher for this research. The DDR is divides into three phases; Phase 1: Need Analysis, Phase 2: Design and Develop, and Phase 3: Implementation and Evaluation. In this study, the researcher focused on Phase 3: Implementation and Evaluation stage to achieve the objective.

\section{RESEARCH INSTRUMENT}

This research is based on the single group comparison study. So, the entire respondent will be required to undergo the process of pre-test and post-test. After the pre-test, the students were given an open ended questionnaire to find out their perception on the experience of doing the drawing in an outdoor environment. In the questionnaire, the researcher also asked the students about which method of teaching and learning of drawing studies that they prefer. The objective of the questionnaire is to seek for the student's preferable method of teaching and learning of drawing studies. Then for the evaluation process, the researcher has selected two (2) expert to evaluate the drawings that have been done through the outdoor learning method and the stimulation process using the standard assessment rubric which is used in the actual drawing studies assessment. In order to get the data of the expert's panels (lecturers) opinions and perceptions, the researcher used semi-structured interview. Mason (2004) stated that semi-structured 
interview has flexible structures and depends on the needs of the research. The targeted population involved in Phase 3: Implementation and Evaluation stage can be divided into two groups. The first group were the students that had undergone the process of pre-test and post-test (stimulation) while the second group consisted of two respondents (expert's panel) who are experts in Art based course field and in Drawing Studies subject. There are also eight students from Art and Design course that have experience in Drawing Studies subject to undergo the pre-test and post-test.

\section{FINDINGS}

Phase 3: Implementation and Evaluation of Stimulation Room for Drawing Studies, there will be a pre-test and post-test that has to be done to complete this research. This is due to the fact that this research, there will be a comparison of the actual outdoor drawing and the stimulation drawing in the studio that been done with the Stimulation Room for Drawing Studies courseware.

\section{Usability Test}

Based on the data gathered from the usability test form that was given by the expert evaluators, the stimulation room for drawing studies courseware were revised and redesigned to suit and comply with the expert comments and ideas. Improvements to the courseware were then carried out. Evaluator 1 found the quality of the video acceptable for drawing purposes as students can still capture the lighting of the scenery and the details required to draw the scenery. This is one of the main focused of the courseware. The main part of the courseware is therefore acceptable. On the point of the sound or audio, it was found to need full audio system and sound proof room, and this requires substantial financial support to implement. This has been recorded as the researcher's limitation in this research. But, still it will be taken as a note for the researcher as a room for improvement for this courseware.

The distraction by the bystanders is also acceptable from the expert Evaluator 1 point of view as the purpose of the video is to capture as actual environment as can be for the student to draw. In the second expert evaluator 
comments, the expert stated that the page and the button design is good and acceptable. The flow of the interface is also clear. It is important for the flow to be clear as this will be easier for the lecturer's or art educator to manage the courseware. This will also save the time for the lecturer to use the courseware without spending much time reading the instruction manual on how to operate the courseware.

The second evaluator also commented on the crowded image on the background of the interface. He stated that it will be clearer if the researcher uses less image to give more impact to the courseware. He also commented on the use of colour of the background. He suggested the use of lighter colour to suit the concept of scenery. The third expert evaluator stated that the button and the icon used in the interface is interesting. The bright colour will attract the user (lecturers) easily when conducting the courseware. The layout of the interface is also clear and provides focus on the objective which is the video and the flow of the interface itself. He also stated that the colour harmony of every page is good and looked nice.

\section{Scenery Drawing Pre-Test (Actual Scenery)}

The student is required to draw the scenery of the waterfall in the duration of one hour. The duration of one hour is suggested by the researcher as the original time for the drawing studies is three hours. During this test, the researcher had the opportunity to see the actual impacts of the outdoor learning method. Unfortunately, the impacts that the researcher observed were rather negative impacts of outdoor learning. The students can't actually focus on their drawing. They were easily distracted and were not able to focus during the outdoor drawing session.

\section{Evaluation 1: The Pre-Test Drawings}

The evaluation of the pre-test was assessing by two (2) expert evaluators. The marks were given by the criteria stated in the marking rubric which is the original marking rubric for drawing studies subject. It consists of the use of medium, the quality of line, the use of proper shading, the differences between foreground and background, image composition, proportion, detailing, neatness and finishing for the drawings. The marks 
The Evaluation and Implementation on the Development of Stimulation Setting using CTMl Model

given by the expert evaluators were in a range of 21 to 42 over 50 .

Table 1: The Pre-Test Drawing Marks

\begin{tabular}{|c|c|}
\hline Marks & No. of Respondents \\
\hline $21 / 50$ & 1 \\
\hline $24 / 50$ & 1 \\
\hline $27 / 50$ & 3 \\
\hline $28 / 50$ & 1 \\
\hline $29 / 50$ & 1 \\
\hline $30 / 50$ & 1 \\
\hline $32 / 50$ & 2 \\
\hline $34 / 50$ & 1 \\
\hline $35 / 50$ & 3 \\
\hline $40 / 50$ & 1 \\
\hline $42 / 50$ & 1 \\
\hline
\end{tabular}

\section{Evaluation 2: The Post-Test Drawings}

In the post-test session, the student will undergo the process of simulation by using the Stimulation Room for Drawing Studies courseware in the drawing studies classroom. The duration of the post-test will be the same with the pre-test. This will ensure there will be no issues of bias that can be brought up in terms of fair comparison. The marks that were given by the expert evaluators were in a range of 23 to 42 over 50 . This shows that the students have performed better from using the stimulation room courseware.

Table 2: The Post-Test Drawing Marks

\begin{tabular}{|c|c|}
\hline Marks & No. of Respondents \\
\hline $23 / 50$ & 3 \\
\hline $25 / 50$ & 1 \\
\hline $26 / 50$ & 2 \\
\hline $27 / 50$ & 2 \\
\hline $32 / 50$ & 1 \\
\hline $33 / 50$ & 3 \\
\hline
\end{tabular}




\begin{tabular}{|c|c|}
\hline $35 / 50$ & 1 \\
\hline $39 / 50$ & 1 \\
\hline $42 / 50$ & 2 \\
\hline
\end{tabular}

\section{Evaluation 3: The Questionnaire}

After the post-test session, the researcher has given the students/ respondent's a set of questionnaire which consist of open-ended questions on their perception and experienced from both the pre-test and the post-test. From the data gathered in the questionnaire, majority of the student vote for outdoor learning method rather than the stimulation room and indoor learning method. This is due to the facts that the student finds it interesting and fun to be outside the classroom. Most of them stated that the reason is to feel the new environment rather than in the conducive classroom surrounding. This point out the interest of the student is to feel more excitement of the open environment itself and not by the ability of the video and audio in the stimulation room courseware and the impacts of it through their drawing. Although the main idea of having this questionnaire is to find out their main ideas and perception on the courseware implementation and its effects on their drawing, the students answer is more based on the environment. But, the data is still acceptable, the students are really interested in having their drawing classes outdoor.

\section{Evaluation 4: Expert Panels Evaluation Interviews on the Student's Pre-Test and Post-Test}

Based on the response of the expert panels through the interviews, we can see that both of the experts have their own opinion and point of view regarding the Stimulation Room for Drawing Studies research. Both of them gave different opinions on the topic. For expert number 1, he stated that he believes that the outdoor learning method has much more to offer the students. He also believes that bringing the student direct to the outdoor can benefit the students more in terms of giving them the proper experience and more knowledgeable as the student can feel the real environment and see the real subject matter.

"From my evaluation, based on two different situations, there are couple of 
factors that can influence whether the assignment was done in a building or outside in nature surroundings. So, I can see here that the factors of surroundings have influence an artist in the making of their artwork. From the perspective views, the focal point of the outdoor is much bigger. So they can choose any angle that they want to suits their desire. So I can say that the vibe in making drawing is better outdoor rather than inside a classroom or studio." (Respondent 1: 29 April 2016)

However, he thinks that the stimulation room can only be as an option. To him, the stimulation room will eliminate the creativity of the student in a sense that the student will only perceive the scenery through visual perception and not really feel or see the reality of the scene. But for expert number 2, she finds the stimulation room as a good intention in art education purposes as it will give a new way and a diversity in teaching and learning of drawing studies. She also stated that from this stimulation room method, she saw that there is an improvement in the students drawing. She believes that through the stimulation room method, the distraction from nature itself can be prevented. She also said that the commitment of the student will be greater as the student will be more focused on their drawing as they will be occupied to the drawing without any distraction. Cost like travelling, food and all the time wasted for applying for consent documentation will also be eliminated due to the facts that the drawing session will be done in a classroom / studio.

"Okay. Actually it is a good intention for educational purposes. Because now when we bring the student for an outdoor activity, which especially related to art, we have to fulfil lots of documentation regarding the guardian consent. After that, it also the factor of financial and the nature's weather. So, if we do the drawing indoor, the commitment of the student will be much greater compare to if we bring them to the outdoor. It is cheaper and the student participation will be more. They can give more commitment indoor compare to the outdoor from my point of view." (Respondent 2: 29 April 2016)

The researcher has shown the process of Phase 3: Implementation and Evaluation. The process was broken down into a series of implementation and evaluation and the results were summarised accordingly. On the pretest and the post-test evaluation by the expert, the comparison of the marks is as follows: 
Expert Evaluator 1:

Table 3: The Pre-Test and Post-Test Drawing Marks from Expert Evaluator 1

\begin{tabular}{|c|c|c|c|}
\hline Respondents & Pre-Test Mark & Post-Test Mark & Difference \\
\hline Respondent 1 & 30 & 23 & -7 \\
\hline Respondent 2 & 27 & 27 & 0 \\
\hline Respondent 3 & 32 & 25 & -7 \\
\hline Respondent 4 & 27 & 23 & -4 \\
\hline Respondent 5 & 35 & 35 & 0 \\
\hline Respondent 6 & 35 & 27 & -8 \\
\hline Respondent 7 & 24 & 23 & -1 \\
\hline Respondent 8 & 35 & 33 & -2 \\
\hline
\end{tabular}

Expert Evaluator 2:

Table 4: The Pre-Test and Post-Test Drawing Marks from Expert Evaluator 2

\begin{tabular}{|c|c|c|c|}
\hline Respondents & Pre-Test Mark & Post-Test Mark & Difference \\
\hline Respondent 1 & 27 & 33 & +6 \\
\hline Respondent 2 & 29 & 42 & +13 \\
\hline Respondent 3 & 21 & 26 & +5 \\
\hline Respondent 4 & 34 & 26 & -8 \\
\hline Respondent 5 & 32 & 39 & +7 \\
\hline Respondent 6 & 40 & 33 & -7 \\
\hline Respondent 7 & 28 & 32 & +4 \\
\hline Respondent 8 & 42 & 42 & 0 \\
\hline
\end{tabular}

From the tables above, it shows that there wasn't much of a difference between the pre-test and the post-test marks that had been given by the expert evaluators. This shows that the Stimulation Room for Drawing Studies method did not provide any difference with the actual outdoor learning method from the student's drawings. It shows that the Stimulation Room method is acceptable and have the opportunity and can be implemented at the tertiary level for the subject of drawing studies. 


\section{CONCLUSION}

Through the Usability Test Form given to the three expert evaluators for the Stimulation Room for Drawing Studies courseware, the researcher managed to get expert feedbacks and comments that will provide the basis for future enhancements of the software. The main points that highlighted by the experts are distraction of the bystanders in the video, and that can be controlled. The sound can be improved with the use of full audio system and using sound proof room/studio, should use less images on the background to avoid confusion and became less attractive and use of lighter colour to suit the theme of scenery drawing. Overall, the expert evaluator gave a positive comment on the courseware. Some of the comments that the expert highlighted have been improved by the researcher. Although the test results show no glaring differences in the student's drawings, the researchers have also taken into consideration the questionnaire that have been given to the students after the post-test. The details of the results have been stated in chapter six. From the questionnaires feedback, it seems that most student prefer the outdoor learning method. They feel like the new experience that they will gain from the activities will widen their mind and can make them feel calmer and focused on their drawings (Beaudry \& Pinsonneault, 2010)

The feedbacks by the students were supported by the first expert evaluator during the researcher in-depth interview with him. He stated that the best way of teaching drawing studies is by the method of outdoor learning. He added that by taking the students outdoor, their angle and view to draw will be wider, thus, making their drawing more realistic. He also stated that the process of simulation will only eliminate student' creativity they will only have visual perception and not going through the real and proper viewing. This is in contrast with the second expert as she thinks that the simulation process is a good way of creating a new method in teaching and learning of drawing studies. She believed with the simulation method, while having the class indoor, the student can give more commitment and more focused on the drawings. She also of the opinion that some students prefer outdoor learning more to the facts that they are looking for fun and excitement than having to be confined in the classrooms. She added that the students are not 100 percent committed to the process of drawing studies. The researcher had gathered the data findings from the expert evaluators from the usability test form, the pre-test and the post-test, the students 
open-ended questionnaire and the expert evaluators semi -constructed interviews. Based on the data gathered, there are strength and advantages of the Stimulation Room courseware and method. However, there is a need for improvement to be done before the method can really be implemented in drawing studies for tertiary level in Malaysia.

\section{REFERENCES}

Anderson, D., Piscitelli, B., Weier, K., Everett, M. \& Tayler, C. (2000). Children's Museum Experiences: Identifying Powerful Mediators of Learning. Curator the Museum Journal, 45(3), 213-231.

Beaudry, A. \& Pinsonneault, A. (2010). The other side of acceptance: Studying the direct and indirect effects of emotions on information technology use. MIS Quarterly, 34(4), pp.689-710.

Dillon, R., Teamey, M., Choi, S. \& Benefield (2006). The Value of Outdoor Learning: Evidence from Research in the UK and Elsewhere. School Science Review, 87(320), 107-111.

Duta Nicoleta, Rivera Oscar Martínez (2014, November). Between theory and practice: The importance of ICT in higher education as a tool for collaborative learning. Paper presented at The $6^{\text {th }}$ International Conference Edu World 2014, Romania.

Karczmarzyk (2012). A Child in the culture of silence? The meaning and communication in children's drawings. Procedia - Social and Behavioral Sciences, 55, 554-559. http://doi.org/10.1016/j.sbspro.2012.09.536

Malone, K. (2008). Every Experience Matters: An evidence based research report on the role of learning outside the classroom for children's whole development from birth to 18 years. Report commissioned by Farming and Countryside Education (FACE) UK Department of Children, School and Families, Wollongong, Australia.

Richey \& Klien (2007). Design Development Research: Method, Strategies and Issues. London: Erlbaum. 
The Evaluation and Implementation on the Development of Stimulation Setting using Ctml Model

Ruskin, J. (1856). The Elements of Drawing. Mineola, NY: Dover Publications Inc.

Salinas, J. (2004). Innovación docente y uso de las TIC en la enseñanza universitaria (Teaching innovation and use of ICT in higher education). Revista Universidad y Sociedad del Conocimiento, 1(1), 1-16. 